\title{
Prácticas académicas y producción de saber de los intelectuales de izquierda en la universidad argentina, 1900-1930
}

\author{
OSVALDO GRACIANO \\ CONICET/Universidad Nacional de Quilmes \\ ograciano@unq.edu.ar
}

\begin{abstract}
Resumen
En las primeras décadas del siglo xx fue visible en Argentina la vinculación de estudiantes, profesionales y de algunos profesores universitarios con las izquierdas, como también lo fue la incorporación en las universidades de docentes que integraban las filas del Partido Socialista. El objetivo de este artículo es reconstruir los rasgos que asumió la experiencia de participación académica y de docencia universitaria de los intelectuales socialistas, focalizando la atención en los casos de Alfredo Palacios, Enrique del Valle Iberlucea y Enrique Mouchet, quienes en esos años habían logrado una importante posición como dirigentes de este partido. Se analizarán así las condiciones de su acceso a la cátedra, su práctica académica, el tipo de trabajo científico llevado adelante por estos profesores y la producción de saber que generaron en su labor universitaria, evaluando los fundamentos de su trabajo científico.
\end{abstract}

Palabras clave: socialismo; universidad; intelectuales; ciencia; práctica académica.

\section{Academic Practices and Knowledge Production of Left-wing Intellectuals in Argentinian Universities, 1900-1930}

\begin{abstract}
In the early 20th century, the link between left-wing intellectuals and students, professionals and some university professors became increasingly visible, as did the incorporation of teachers belonging to the Socialist Party into universities. This article seeks to reconstruct the characteristics of socialist intellectuals' experience of academic participation and university teaching, focusing on the cases of Alfredo Palacios, Enrique del Valle Iberlucea and Enrique Mouchet, who achieved key leadership positions in the party during this period. It analyzes the conditions of access to teaching, academic practice, the type of scientific work carried out by the professors and the knowledge produced in their university work, assessing the bases of their scientific work.
\end{abstract}

Key words: socialism; university; intellectuals; science; academic practice. 


\title{
Prácticas académicas y producción de saber de los intelectuales de izquierda en la universidad argentina, 1900-1930*
}

\author{
Osvaldo Graciano
}

A un con el expreso rechazo por parte de algunos grupos de profesores que lo interpretaron como la instauración de la enseñanza de la rebelión y la anarquía contra el orden en la universidad, en las primeras décadas del siglo XX se incorporaron en sus cátedras figuras que militaban en el Partido Socialista (en PS). No se trató de un proceso de incorporación masivo y en algunos casos tampoco fue permanente, pero sí fue visible por la prominencia política alcanzada por algunos de ellos en ese partido, como en los casos de Juan B. Justo, Nicolás Repetto, Alfredo Palacios, Enrique del Valle Iberlucea y Enrique Mouchet. También fueron numerosas, aunque muchas veces breves, las militancias de estudiantes universitarios y de profesionales en las filas del Ps y en las del anarquismo, como ilustran los casos de José Ingenieros y José Pascali en el primero, y

\footnotetext{
* Una versión preliminar de este trabajo se presentó en las Jornadas Universidad, Intelectuales y Vanguardias en la Argentina. Primera mitad del siglo Xx. Estudios y perspectivas de investigación, realizadas en la Universidad Nacional de Quilmes, los días 21 y 22 de marzo de 2013. Agradezco los comentarios formulados por sus participantes así como también los realizados por los evaluadores anónimos de la revista.
}

de Pascual Guglianone en el segundo. Pero fue el ps el que desde sus orígenes hizo muy visible ese vínculo y el hecho que mejor lo demuestra fue el predominio temprano que en su dirección tuvieron los médicos, los abogados y los ingenieros. ${ }^{1}$

La experiencia universitaria fue así un factor que influyó tempranamente en el segmento de los militantes de izquierda provenientes de las clases medias que cursaron sus estudios en la universidad de fines del siglo XIX, en la elección de incorporarse a una de sus fuerzas. Pero fundamentalmente lo fue en determinar un lugar expectante en sus filas, de cara a desarrollar una carrera política en ellas, por sobre los militantes obreros. La condición universitaria influyó sin dudas en sus carreras partidarias: el prestigio social que otorgaba el título como expresión máxima de la cultura letrada, el dominio de la oratoria y la escritura, la posesión de un saber científico, fueron aspectos que gravitaron a la hora del debate interno y de las postulaciones a los cargos partidarios y electivos. Este vínculo con el mundo letrado fue evidente también en el PC argentino, creado a partir de la conmoción política

\footnotetext{
${ }^{1}$ Sobre el desarrollo del PS en este periodo, véase Adelman (1992, pp. 211-238); Camarero y Herrera (2005); Walter (1977).
} 
mundial del ciclo revolucionario europeo de la primera posguerra y que incorporó en sus filas a estudiantes y profesionales como Alberto Palcos, Paulino González Alberdi y al ya citado Pascali, aunque el itinerario del partido en los años veinte no llevó a la consolidación de estos en su dirección (Camarero, 2007).

El cambio político democrático iniciado en 1912 y los educativos en las universidades impulsados por la reforma universitaria de 1918, como la influencia que ejerció sobre la intelectualidad argentina la revolución bolchevique, hicieron a su vez posible a un sector del profesorado y del movimiento estudiantil, otorgar en los años veinte un lugar de difusión y de análisis científico en la cátedra, a las ideologías y doctrinas económicas socialista y marxista y a los procesos revolucionarios a que dieron lugar en Europa. Debe indicarse, sin embargo, que la recepción del marxismo en la universidad fue visible desde temprano, siendo tema de análisis sistemático en la cátedra por parte de intelectuales de la elite dominante como Ernesto Quesada, y de modo puntual por parte de otros, así como de los jóvenes abogados socialistas Alfredo Palacios y Enrique del Valle Iberlucea, a través de conferencias y breves artículos. ${ }^{2}$ Pero fue a partir de la influencia estudiantil en la nueva década que algunas facultades

\footnotetext{
${ }^{2}$ El estudio que Quesada promovió del marxismo fue complejo, pero desde una lectura defensiva del orden social: su objetivo era cuestionar científicamente la validez teórica y política de su aplicación a la realidad argentina para su transformación. Véase al respecto Pereyra (1999, pp. 41-56). Para un análisis integral de las lecturas de Marx realizadas por universitarios liberales y socialistas, Tarcus (2007, pp. 409-491).
}

- como las de Derecho de Buenos Aires y de La Plata-, incorporaron su estudio en los programas de algunas materias, mostrando un cambio sustantivo para emprenderlo: ese estudio se inscribía en el escenario histórico mundial de la primera posguerra, que modificó totalmente la labor intelectual sobre el marxismo, llevando a su abordaje ya no sólo como una teoría social, sino como una doctrina política cuyos principios dirigían el proceso político sobre el cual el proletariado europeo construía un nuevo orden social. ${ }^{3}$

Vale aclarar que la vinculación de muchos universitarios con el anarquismo, el socialismo y el comunismo no generó en su interior programas para la transformación de la universidad, ya que la extendida interpretación de las casas de altos estudios en estos movimientos fue la de definirlas como un aparato cultural controlado por los sectores dominantes y de formación profesional de sus núcleos dirigentes. Su corolario fue un juicio categórico sobre su nulo aporte al desenvolvimiento educativo, científico-cultural y político-social del país. Sólo las protestas estudiantiles de 1918 movilizaron a socialistas y anarquistas para reclamar cambios profundos en la enseñanza universitaria y

${ }^{3}$ Su estudio en la universidad posterior a 1918 tuvo un relevo social evidente, pues fue desplegado de modo excluyente por intelectuales reformistas y de izquierda provenientes de las clases medias de origen inmigrante, así como también su difusión fue emprendida a través de cursos libres y conferencias, confiadas a intelectuales argentinos y extranjeros que simpatizaban con la experiencia bolchevique. Pero expresó además una paradoja: en el momento histórico de su apogeo como ideología fundante de una sociedad socialista, resulta difícil encontrar en las cátedras argentinas cursos de estudios sistemáticos del marxismo. Graciano (2008, pp. 91-118). 
apoyar sus propuestas. Pero esa mirada crítica omitía, sin embargo, la específica articulación que las tres universidades existentes en el país guardaban con el sistema político y con la burocracia estatal (muy visibles durante el régimen oligárquico), a partir de la cual aquellas fueron capaces de formar a sus cuadros políticos y técnicos. Esta articulación entre política y universidad y entre esta y el Estado fue puesta a la luz en distintas investigaciones historiográficas y sociológicas (Buchbinder, 2005; Zimmermann, 1995). ${ }^{4}$

Puede afirmarse también que el lazo entre estas fuerzas políticas y los universitarios no fue excepcional ni contingente a lo largo de la primera mitad del siglo $\mathrm{xx}$ y fue particularmente en el PS en donde se hizo más visible, ya que muchos de sus dirigentes e intelectuales eran egresados de las universidades teniendo asimismo una presencia dominante en su dirección. ${ }^{5}$ En este artículo se reconstruyen la docencia universitaria y la actividad académica llevadas adelante por Alfredo Palacios, Enrique del Valle Iberlucea y Enrique Mouchet, egresados de la universidad ar-

\footnotetext{
${ }^{4}$ Otros estudios sistemáticos desde las ciencias sociales para comprender los vínculos entre conocimiento social y Estado y la formación de categorías de científicos y expertos, son Bohoslavsky y Soprano (2010); Fréderic, Graciano y Soprano (2010); Neiburg y Plotkin (2004). Para una perspectiva latinoamericana sobre el papel de los abogados como hombres de Estado, véase Pérez (2008).

${ }^{5} \mathrm{Si}$ bien se trató de un partido con importante número de afiliados y de votantes obreros, no menor fue el de empleados, artesanos y pequeños comerciantes. Pero la participación de universitarios en sus filas y en sus listas de candidatos siempre fue numerosa, un hecho muy visible en la ciudad de Buenos Aires y en La Plata, la capital de la provincia de Buenos Aires. Véanse Graciano (2008); Walter (1977, pp. 174-176).
}

gentina y que al mismo tiempo que desplegaron una extensa trayectoria como docentes en ella militaron en el socialismo. Aun en lo arbitrario que toda selección temática y construcción del objeto de investigación tiene por parte de un historiador o de cualquier científico social (ya sea por la selección del enfoque y el diseño metodológico, de las variables puestas en evaluación o del recorte del periodo y la clasificación de fuentes, entre otros aspectos) su estudio se justifica por el hecho de contarse entre los primeros socialistas que tuvieron acceso a cátedras universitarias y desarrollaron en ella una prolongada carrera académica. A lo largo de estas páginas se analizan las condiciones de su acceso a la cátedra, las características de su práctica académica y del tipo de trabajo científico y de producción de saber que llevaron adelante. El estudio de su obra permite evaluar en qué medida la cátedra fue el espacio de esa producción $y$, no menos importante, los fundamentos del trabajo científico que desplegaron. El abordaje privilegiado en este trabajo se concentra en la reconstrucción de los itinerarios intelectuales de estos universitarios, focalizando la escala de análisis en sus carreras y haciendo hincapié en la evaluación de sus prácticas académicas singulares y de la producción científica a que ellas dieron lugar. Se pretende desde este enfoque echar luz sobre una de las formas que asumió la experiencia intelectual de los hombres de izquierda que detentaban títulos profesionales en las primeras décadas del siglo Xx y que tuvo lugar en la universidad. ${ }^{6}$ Sin embargo, a pesar del

\footnotetext{
${ }^{6}$ Vale aclarar que la producción escrita de estos universitarios es profusa y en función de los objetivos de este artículo, sólo se identifican y analizan las que
} 
hecho ampliamente constatado por la historiografía argentina de la extensa trayectoria e influencia en las universidades de los profesionales socialistas como los aquí estudiados, se trata de una temática que cuenta sólo con una escasa exploración sistemática. ${ }^{7}$

Debe remarcarse que el análisis emprendido en este artículo es posible también por la consolidación de una serie de estudios que reconstruyeron la historia de la universidad y de la cultura académica que en ella se constituyó, atendiendo precisamente a los proyectos y a las experiencias educativas y científicas que en su interior desplegaron sus cuerpos de profesores, sus científicos y el movimiento estudiantil, redefiniendo desde esas claves el desenvolvimiento institucional de las casas de altos estudios. Esta historiografía hace posible inscribir en ella las trayectorias docentes y científicas de Palacios, de Del Valle Iberlucea y de Mouchet que no sólo tuvieron una extensa duración, sino que también influyeron en la modelación de las características que la práctica científica y docente fue tomando en el periodo aquí estudiado. ${ }^{8}$ Este artículo se inscribe también en la trama de los estudios de la historia intelectual, un campo de investigación plenamente consolidado en Argentina. Sin embargo, se ofrece en él un enfoque metodológico diferenciado

se vinculan más estrechamente a su labor como profesores y a aquellas que, aun teniendo un origen vinculado a su actividad partidaria, se publicaron en revistas académicas.

${ }^{7}$ Entre los trabajos sistemáticos desde esta perspectiva, véanse Becerra (2009); Graciano (2003a, 2008, 2010).

${ }^{8}$ Véase al respecto Altamirano (2004); Biagini (1999); Buchbinder (1997, 2005); Vallejo (2007). para la reconstrucción de las trayectorias de los universitarios y de su producción de saber, que vincula las dimensiones de su actividad científico-académica en la universidad con las de su condición de clase inscritas en sus biografías y, no menos importante, las de su experiencia políticoideológica y partidaria, entendidas siempre como dimensiones de una práctica social intelectual singular y unívoca que los tiene como protagonistas y que condiciona sus elecciones ideológicas, apuestas políticas e intervenciones intelectuales, como también sus orientaciones y especializaciones disciplinares. ${ }^{9}$ Esta perspectiva posibilita analizar a la vez las condiciones de su producción de conocimiento en la universidad y el tipo de saberes que elaboraron en su seno, como resultado de una práctica intelectual condicionada por diversas dimensiones: las propias de su actuación en el espacio universitario, pero también las constitutivas de sus intervenciones en la esfera cultural y en la política partidaria.

\section{BIOGRAFÍA, FORMACIÓN ACADÉMICA E INCORPORACIÓN A LA ENSEÑANZA UNIVERSITARIA.}

El enfoque biográfico permite analizar los itinerarios académicos de Palacios, de Del Valle Iberlucea y de Mouchet, reconstruir sus perfiles de formación profesional y su elección de una carrera docente universitaria, y atender también a las expectativas sociales y culturales familiares que en esas elecciones influyeron. La sociabilidad de su infancia y primera juventud, la esco-

\footnotetext{
9 Sobre este enfoque véanse los trabajos de Altamirano (2001, 2006); Neiburg y Plotkin (2004).
} 
larización, etapas decisivas en la formación de su personalidad y de generación de expectativas, permiten visualizar las condiciones y factores familiares, educativos y político-culturales que influyeron en sus identidades personales e inferir si gravitaron en sus elecciones de las carreras universitarias.

Nacido en la ciudad de Buenos Aires en 1878, Palacios era miembro de una familia criolla rioplatense formada en abierta contradicción de los convencionalismos del matrimonio católico, ya que su padre, el político uruguayo Aurelio Palacios, había constituido otra anteriormente sí reconocida por la Iglesia católica. Recibiría asimismo una formación escolar laica en los niveles primario y secundario (escolarización que atravesaría la coyuntura de secularización liberal de la sociedad de la década de 1880) y egresaría como abogado en 1900. En su elección de la carrera de Derecho debió influir el diktat social paterno, ya que su padre era un jurista reconocido, egresado de la facultad en la que Alfredo y otro de sus hijos también la cursarían. La figura paterna pudo ser también un modelo en instar a la temprana preocupación de Alfredo por la política, ya que aquel fue un dirigente del partido Blanco uruguayo y participó en la vida política argentina. Pero la materna fue decisiva en su temprana formación católica, que lo llevó a integrarse -aún siendo estudiante secundario- a los Círculos de Obreros Católicos organizados por el cura Federico Grote (García, 1998). Pero su preferencia por los estudios de abogacía muestra bien el curso de promoción social que tenían las familias criollas porteñas de clase media y condición letrada y el peso de una tradición de "doctores" fundada por su padre. Su ingreso en la Facultad de Derecho y Ciencias Sociales de la Universidad de Buenos Aires en 1896 lo inscribió en un espacio institucional trazado por las cuestiones laicas y liberales del derecho, la ciencia y la política. Esta formación jurídica, fundada en una ciencia dominada por el positivismo evolucionista, lo alejó del movimiento católico, siendo a su vez una de las condiciones para su acercamiento al PS.

Del Valle Iberlucea era el contrapunto social de Palacios, ya que pertenecía a una familia española de inmigración reciente al país (él mismo extranjero, ya que había nacido en Castro Urdiales, en 1877), que se instaló en Rosario. Pero en términos culturales y políticos se formó en espacios de sociabilidad similares: el hogar familiar tenía como cabeza a un padre republicano (este fue uno de los motivos de la emigración de la familia) y esa experiencia fue reforzada por una escolarización media liberal-positivista (asistió al bachillerato del Colegio Nacional de aquella ciudad) y por una trama de vínculos personales que tejió ese estudiante con algunos de sus profesores durante su juventud, que lo llevaron a participar en cenáculos y revistas culturales liberales de la ciudad promovidos por ellos y los estudiantes del colegio. Pero ya desde esos años se relacionó con el socialismo de la ciudad. Su carrera universitaria estaría marcada tanto por su condición de extranjero (recién obtuvo su carta de ciudadanía argentina en 1902) y la de "provinciano", ya que debió trasladarse desde Rosario a Buenos Aires para llevarla adelante (véase Solari, 1972, y en particular Becerra, 2009).

En tanto los datos biográficos de Enrique Mouchet permiten ubicarlo en una 
trama de vida familiar y escolar pautada por rasgos sociales y en particular de sociabilidad cultural y políticos cercanos a los de Del Valle Iberlucea, ya que integró un hogar porteño de clase media de origen francés. Si bien algo más joven que aquellos (nació en 1886 en Buenos Aires), probablemente desarrolló sus estudios de bachillerato en el Colegio Normal de Profesores de la ciudad y los universitarios en la Facultad de Filosofía y Letras, de la que egresó en 1910 como doctor en Filosofía, y en la de Ciencias Médicas, en la que se graduó en 1914.

Todos ellos vivieron la vertiginosa modernización social y económica del país y la transformación de Buenos Aires en una ciudad moderna. El mundo social en el que estos jóvenes vivieron inauguró otras realidades para las familias de la elite y para las de los sectores medios, ya fueran criollos o inmigrantes. En efecto, la consolidación definitiva del Estado y de un sistema político liberal, la secularización de la vida pública y la transformación profunda de la sociedad, con la gran inmigración y la emergencia de esas clases medias, de partidos políticos y de un movimiento obrero con gran presencia extranjera y capacidad de protesta social, fue el nuevo escenario de sociabilidad en el que insertaron sus vidas de estudiantes de Derecho los jóvenes Palacios y Del Valle Iberlucea, y de Filosofía y Medicina en el caso de Mouchet (Rapoport y Seoane, 2007, t. 1, pp. 108-219).

La Universidad de Buenos Aires también vivió esos procesos de cambios institucionales, académicos y curriculares con su nacionalización y los de tipo social, como demostró el ingreso a sus carreras de Derecho y de Medicina de hijos de familias inmigrantes que integraban las clases medias, los que fueron testimoniados por las propias autoridades universitarias con alarma. Si ese fenómeno afectó principalmente a las carreras de Medicina e Ingeniería, fue visible también en la de Derecho y en las que se cursaban en la novísima Facultad de Filosofía y Letras (Buchbinder, 2005, pp. 74-76; Halperin, 2002). Pero la inmigración no era sólo un hecho social registrable para cualquier porteño en su vida cotidiana, sino que se inscribía, por un lado, en sus propias instituciones políticas, en sus leyes y en la obra de los gobiernos nacionales. También, por el otro, aparecía en la forma de las numerosas huelgas y protestas anarquistas que emergieron en el cambio de siglo, en el avance de la organización sindical del socialismo y en la política de este movimiento, con la fundación del PS. El fenómeno social era motivo de interés científico en la universidad: $\mathrm{Pa}$ lacios desarrolló en 1899 su curso de Sociología con Antonio Dellepiane en la Facultad de Filosofía y Letras y su tema de estudio fue la "Condición de la clase obrera en Buenos Aires”, interesándole el fenómeno de la inmigración en su lado oscuro, el de las condiciones laborales y la situación de miseria de los trabajadores, y el del activismo sindical y político obrero.

Tanto Del Valle Iberlucea como Palacios cursaron sus estudios en la Facultad de Derecho de la Universidad de Buenos Aires contemporáneamente y pudieron coincidir en cursos y vínculos académicos en ella, como seguramente compartieron el mismo núcleo de profesores, quienes se desempeñaban a la vez como intelectuales, jueces, altos funcionarios y políticos del régimen oligárquico (Joaquín V. González, Wenceslao Escalante, Osvaldo Magnasco 
y Manuel Obarrio, entre otros). Las carreras de Del Valle Iberlucea y de Mouchet concordaron a su vez en un recorrido común para algunos estudiantes del periodo y que era realizar estudios en la novísima Facultad de Filosofía y Letras. Pero mientras para el primero fueron posteriores a los de Derecho y fue evidente que sirvieron de complementación para su especialización profesional en Historia e Historia del Derecho Internacional, para Mouchet los estudios de Psicología fueron los iniciales de su formación universitaria. En efecto, este último se graduó en 1910 con una tesis sobre psicología (aunque su diploma lo acreditó como doctor en Filosofía) titulada "Examen del concepto de identidad". Pero sus intereses intelectuales de especializarse en psicología médica según Vezzetti, lo llevaron a realizar al mismo tiempo la carrera de Medicina, que completó en 1914 (Foradori, 1941, p. 11; Vezzetti, 1996b, p. 23).

Su realización de estudios en diversas facultades de la Universidad de Buenos Aires revelaba también las vinculaciones entre algunas de esas carreras, por lo menos en el hecho de que compartían los mismos profesores y que por lo tanto construían tramas de especialización profesional, de temáticas y de labor intelectual que las atravesaban. Ellas también influían en las orientaciones electivas de los estudiantes: bajo el discipulado del médico Horacio Piñero (que se desempeñaba como profesor de psicología en la Facultad de Filosofía y Letras y de fisiología en la de Ciencias Médicas), Mouchet se vinculó a sus cátedras y, como se señaló antes, continuó sus estudios de medicina, especializándose en Psicología Experimental, graduándose en esta carrera con una tesis cuyo tema aplicaba los enfoques de aque- lla disciplina: "Introducción a la fisiología y patología del espíritu”. Mouchet realizó así dos carreras universitarias de modo simultáneo (iniciando ambas en 1908) y las titulaciones que obtuvo operaban como complementaciones de su formación como psicólogo experimental. ${ }^{10}$

En sus extensas carreras de estudiantes, que duraban entre cinco y seis años (y que podían extenderse por dos o tres más para alcanzar una segunda titulación, iniciada al mismo tiempo que la primera o ya avanzada esta) tuvieron gran influencia los vínculos discipulares que establecieron con los profesores en sus cursos, en los cuales desarrollaron formas específicas de trabajo científico, definieron orientaciones temáticas y de especialización que los marcaría decididamente en sus carreras como egresados. Los discipulados que, sin duda, se continuaban más allá de las aulas, son un aspecto poco conocido aún y que sin embargo es relevante para el análisis de las prácticas académicas de los universitarios. Así, como ya se indicó, este tipo de vínculo educativo fue decisivo para la especialización en Psicología Experimental de Mouchet, quien como estudiante participó en los cursos de psicología que dictaba Piñero. También lo fue para la orientación profesional de Del Valle Iberlucea en historia, derecho político e internacional, el dictado de clases aún como estudiante, como las que expuso en 1901 en la cátedra de Derecho Constitucional y que dieron lugar a su libro Derecho político ese mismo año. En él expuso los tópicos

${ }^{10}$ La carrera de Palacios también ilustra esta trama educativa concurrente de profesores y materias entre distintas facultades, ya que como se indicó cursó, con Dellepiane, Sociología en la Facultad de Filosofía y Letras. 
del derecho político dando un lugar específico al análisis del socialismo y del marxismo. No menor fue la realización de su tesis para optar al título de doctor en Jurisprudencia, bajo la orientación de los profesores Joaquín V. González y Pedro O. Luro. Titulada "El procedimiento judicial en el derecho internacional" y aprobada en 1902, su tesis mostraba bien la influencia de algunos profesores y los vínculos construidos con ellos a lo largo de sus carreras. ${ }^{11}$

El caso diferenciado fue el de Palacios, quien presentó como tesis para obtener su título de doctor en Jurisprudencia el trabajo "La miseria (estudio administrativo legal)", en la que expuso la explotación y miseria obrera y una dura crítica del régimen conservador. Rechazada por el jurado examinador con un argumento formal (la tesis contravenía para este el artículo 40 de la reglamentación universitaria), la razón real fue la denuncia del régimen político como oligárquico y venal, la crítica de la institucionalidad jurídica burguesa como privilegio de clase y el análisis sociológico de la situación de la clase obrera en el país desde un enfoque socialista, posiciones académicas que el profesorado de la facultad, integrante de la elite dominante y en gran parte del poder político y estatal, era imposible que aprobara. ${ }^{12}$ Palacios pare-

${ }^{11}$ Según Becerra, Del Valle Iberlucea postuló en su tesis la inclusión del divorcio en la legislación argentina y la plenitud de los derechos civiles de las mujeres. Becerra (2009, pp. 14-15).

${ }^{12}$ El jurado de tesis de Palacios estuvo integrado por David de Tezanos Pinto, Wenceslao Escalante, Raymond Wilmart, Osvaldo Piñero, Enrique Obarrio y Ángel Pizarro, algunos se desempeñaban en la alta burocracia y la magistratura. Véase García (1988, p. 243); Tarcus (2007). cía haberse conducido sin la dirección explícita de algún profesor de la facultad que avalara su tesis, aunque él reconociera en ella la continuación del trabajo de seminario iniciado con Dellepiane. Sin embargo, ese rechazo no detuvo sus aspiraciones profesionales, ya que presentó a los pocos meses una nueva tesis titulada "Quiebras". Acorde a las orientaciones jurídicas y condiciones académicas dominantes en la facultad, finalmente fue aprobada sin inconvenientes.

La afiliación de estos tres universitarios al Ps una vez egresados de sus carreras, no fue así sorpresiva, sino que respondió a un acercamiento ideológico temprano y a un vínculo ya construido desde sus respectivas etapas estudiantiles con ese movimiento y sus ideas, revelando un interés por la política y la cuestión social que atravesaba a los jóvenes universitarios, aun antes de conformarse los centros estudiantiles y desatarse sus primeras protestas importantes. A pesar de que durante los años de bachillerato y de universidad se habían vinculado en relaciones discipulares con profesores de posiciones jurídicas y políticas liberales que eran hombres del régimen político, y habían definido en esas carreras un habitus escolar que marcaría todo su trabajo intelectual $-y$ preparándose (según el discurso de las autoridades universitarias) como la futura "clase dirigente del país"-, se adscribieron a las filas socialistas. Su opción por el socialismo debe buscarse en las dimensiones sociales y culturales de sus condiciones tanto etaria como de clase: como jóvenes estudiantes de los sectores medios urbanos metropolitanos, fueron influidos por la prédica democrático-igualitarista que el PS dirigió hacia ellos y por la radicalidad antiburguesa de los círculos de la bohemia 
literaria porteña que frecuentaron en esos años. $^{13}$

Esas mismas dimensiones socioculturales jugaron como obstáculos a su acercamiento político a los profesores universitarios que no sólo eran intelectuales de los sectores dominantes por ser una meritocracia del saber, sino que por su propio abolengo social la integraban, expresando valores y visiones del mundo distintas y antagónicas a las de estos jóvenes. Pero fueron también sus estudios medios y universitarios (y el acceso a través de ellos a una bibliografía entre la que se contaban la socialista, la anarquista y la marxista), los que les posibilitaron el análisis crítico del orden social y político nacional, y encontrar en el socialismo un movimiento político que brindaba soluciones teóricas y científicas a las falencias de ese orden. ${ }^{14}$ Pero si su cooptación al régimen conservador no fue ideológica ni política, ella se dio bajo la forma educativa y científica, con sus incorporaciones a una universidad y docencia conformadas plenamente por intelectuales de la elite, al mismo tiempo que desarrollaban su militancia socialista.

13 Tarcus (2007, pp. 445 y 449) señala los vínculos juveniles de Del Valle Iberlucea y de Palacios con escritores de esa bohemia y de este último con la revista de Ingenieros y Lugones, La Montaña.

${ }^{14} \mathrm{La}$ dirigencia socialista, universitaria y positivista, creía firmemente en que la ciencia era un instrumento social para la transformación del país, con su función de proveer saberes y respuestas a los problemas de la sociedad y que era el socialismo su misma encarnación. Para difundir los conocimientos científicos entre los trabajadores, se valió de su prensa y de las bibliotecas y ateneos que fundó tempranamente. Véase Barrancos (1996).
Trayectoria aCAdÉmica de ENRIQUe DEL VALLE IBERLUCEA

Los inicios de la carrera docente de Del Valle Iberlucea responden sin dudas a su acumulación exitosa de capital científico con sus títulos de doctor en Jurisprudencia y en Filosofía y Letras y a sus tempranas publicaciones sobre cuestiones del derecho político y civil. Pero los vínculos personales que estableció con Joaquín V. González, profesor de la Facultad de Derecho porteña durante la dirección de su tesis y luego al participar en 1904 en la elaboración del proyecto de código nacional de trabajo del mismo González (ministro del Interior del gobierno de Julio A. Roca), fueron decisivos para que fuera invitado por él a participar de su plan de organización de la nueva Universidad Nacional de La Plata (UNLP). En efecto, Del Valle Iberlucea fue nombrado secretario general de la recién fundada UNLP y del Consejo Universitario en 1905, desempeñando esos cargos hasta 1913. Inició así una carrera académica incorporado a su estructura de gobierno, colaborando con autoridades y docentes que integraban el pináculo de la ciencia positivista, todos intelectuales liberales y comprometidos con el régimen oligárquico: entre ellos se contaban además de González, Agustín Álvarez, Rodolfo Rivarola, Ernesto Quesada, Luis María Drago, Manuel A. Montes de Oca y José N. Matienzo. En ese cargo Del Valle Iberlucea acompañó a González y a los consejos superiores en todas las resoluciones que permitieron organizar las facultades, institutos y escuelas de la universidad, nombrar a sus autoridades, poner en marcha sus carreras y organizar tanto los ciclos de intercambio académico con profesores y 
científicos europeos como la extensión universitaria (UNLP, 1910).

La condición de socialista de Del Valle Iberlucea, conocida ampliamente, no había obstaculizado su nombramiento y sin dudas su reconocimiento como parte de ese movimiento gravitó en su designación, ya que la UNLP se fundó con el objetivo explícito de estudiar científicamente la cuestión obrera. La nueva institución continuaba en el espacio universitario los estudios que parte de la dirigencia liberal liderada por González había impulsado desde el mismo Estado en esos años (Zimmermann, 1995, pp. 68-74). Su integración al círculo de profesores de la UNLP que integraban la elite científica de principios de siglo, se dio también por compartir con ellos los fundamentos positivistas y evolucionistas de la misma, y por sus inquietudes por desplegar una labor académica que diera bases científicas a las cuestiones políticas y sociales, que parte de ese profesorado tenía en su agenda intelectual. Del Valle Iberlucea fue un activo impulsor de la extensión universitaria de la nueva casa de estudios, participando en sus ciclos de conferencias y cursos y en las actividades de intercambio universitario que implementaron con reconocidos publicistas españoles de reformas sociales, como en el caso del jurista Adolfo Posada (Zimmermann, 1995, pp. 73-74). El joven profesor socialista compartía con ese grupo de la ciencia académica positivista, una convicción educativa sobre una tarea universitaria superadora del profesionalismo, que buscaba convertir a la UNLP en un ámbito de investigación científica en el terreno de las ciencias físicas y naturales, así como de las disciplinas sociales y profesionales (Buchbinder, 2005, pp. 81-91). Pero era también evidente que los vínculos personales y profesionales de Del Valle Iberlucea con González fueron decisivos para llevarlo a participar de la organización de la nueva universidad, integrándolo al núcleo de su dirección académica con una carrera profesional recién iniciada y con sólo 28 años. Su docencia universitaria comenzó en la misma UNLP: primero acompañó a González en su cátedra de Derecho Internacional Público en la Facultad de Ciencias Jurídicas, de la que fue designado profesor suplente en 1908. Poco después consolidaría esa posición académica (que para nada mostraba marginalidad en el sistema educativo estatal), siendo nombrado en 1914 titular de Derecho Internacional Público y accediendo a una cátedra de Historia de la Civilización en la Facultad de Filosofía y Letras porteña y a otra de Historia Moderna y Contemporánea en el Colegio Nacional de Buenos Aires.

Sin embargo, esas posiciones académicas y esas relaciones universitarias no pueden llevar a pensar en una cooptación intelectual, ya que su labor profesional no se limitaba a ellas. En efecto, en su militancia en el Ps, Del Valle Iberlucea estableció un fuerte vínculo entre su profesión y la política partidaria, ya que desde 1905 y junto con Palacios atendió un consultorio jurídico de la central socialista Unión General de Trabajadores. Pocos años después (en 1910) creó el Ateneo Popular, junto con otros universitarios (entre los que estaba Enrique Mouchet) con el fin de dictar cursos y conferencias entre los obreros. Esta acción partidaria se completó con su pretensión también de incidir en su discusión ideológica, fundando en 1908 la Revista Socialista Internacional (pocos años después renombrada como 
Humanidad Nueva) desde la que propuso difundir textos doctrinarios marxistas, educativos y científicos (Tarcus, 2007, pp. 456-458). Ese Ateneo Popular era una variante socialista de la vulgarización científica universitaria y estuvo influido por la que el mismo Del Valle Iberlucea gestionaba desde la UNLP, lo que se expresó en el hecho de que algunos profesores de esta participaron allí, dictando conferencias o cursos. Los vínculos, por ejemplo, entre estas experiencias de extensión eran estrechos hasta en sus temáticas, referidas en parte a la problemática obrera y las ideas del socialismo, y se ejemplifican bien con la conferencia que Del Valle Iberlucea brindó en una y otra institución sobre marxismo titulada "Teoría materialista de la historia”. En su exposición de la misma en la universidad platense (de agosto de 1906), Del Valle Iberlucea ensayó ante su auditorio (formado además de legos, por estudiantes y por algunos de sus propios colegas) un balance de la historiografía nacional, señalando la carencia de un estudio científico del pasado argentino y postulando que ese enfoque se asociaba a la aplicación a ella del materialismo histórico. Esbozaba de ese modo una conceptualización y un programa de lo que debía ser la investigación histórica, cuyos resultados en términos de la interpretación de la historia argentina llevarían a visualizar los factores económicos y la lucha de clases en su desenvolvimiento. Pero su importancia no era menor en términos políticos y sociales, ya que Del Valle Iberlucea (1929) descubriría a las masas, bajo el nombre genérico de "pueblo", como protagonista decisivo de esa historia. Así lo sintetizaba:

Hasta ahora, señores, hemos hecho en la república la historia de los héroes y de los grandes personajes; pero es necesario que en adelante procuremos escribir su historia científica, y sólo lo conseguiremos cuando empleemos el método señalado por el materialismo histórico: es posible que con ese sistema reduzcamos la magnitud de ciertos cuadros y de ciertos hombres; pero, en cambio, aparecerá con más relieve una entidad anónima que hizo la revolución y creará la grandeza de la república: el pueblo (p. 185).

Los escritos de Del Valle Iberlucea estuvieron particularmente condicionados por su itinerario entre su carrera académica y el ejercicio profesional, la gestión universitaria platense y su militancia política: así, mientras sus primeras publicaciones refirieron a cuestiones jurídicas y de derecho político, luego las mismas fueron el resultado tanto de su labor institucional universitaria como de su acción en el PS. Entre las primeras se encuentran sus libros Derecho político (1901) y El procedimiento judicial en el derecho internacional privado (1902), y entre las segundas la ya citada Teoría materialista de la historia y también Industrialismo y socialismo en la República Argentina (1909). ${ }^{15}$

Pero su afianzamiento en las cátedras universitarias le permitió desarrollar una investigación de aspectos de la historia independentista rioplatense, que dieron lugar a su libro Los diputados de Buenos Aires en las cortes de Cádiz. Nuevo sistema de gobierno económico de América y al breve texto Las cortes de Cádiz. La revolución de España. La democracia de América, ambos publicados en 1912. En la Facultad de Filosofía y Letras participó en la obra colectiva de

${ }^{15}$ Para una síntesis general de la obra de Del Valle, véase Corbière (1987, pp.16-17); Tarcus (2007, p. 177). 
recopilación documental promovida por Luis María Torres y Emilio Ravignani, Documentos para la bistoria argentina, colaborando con la edición del libro de Miguel Lastarria Colonias orientales del Río Paraguay o de la Plata, editado por esa unidad académica en 1914 (Buchbinder, 2005, pp. 76-77). Una tercera obra, que fue también resultado de su tarea docente en esa facultad (pero que estuvo motivada por la crisis europea que llevó a la guerra) fue La guerra europea y la politica internacional. Lecciones sobre la bistoria de las relaciones internacionales de Europa en el siglo XIX, dictadas en la Facultad de Filosofía y Letras, siendo publicada en 1914.

En todos estos escritos su labor se caracterizaba por el dominio e instrumentación de la historiografía positivista y del canon bibliográfico jurídico en materia de derecho político e internacional, experticia profesional reconocida por sus pares (Becerra, 2009, pp. 44-61). Sus aportes en ellas iban desde ensayar la interpretación marxista de los hechos históricos, a proponer la defensa del divorcio y la igualdad civil en el derecho de las mujeres, y de una juridicidad que contemplara los derechos sociales y obreros. Pero salvo algunos de sus libros jurídicos e historiográficos, sus trabajos revelaban una tarea más ensayística y de interpretaciones bibliográficas exhaustivas, de lecciones y conferencias de cátedras y cursos libres, más que ser despliegues de investigaciones empíricas ampliamente documentadas. Sus estudios de la historia independentista hispanoamericana como los de la historia política europea del siglo XIX y la coyuntura de la guerra mundial, no pueden ser definidos como el resultado de una interpretación marxista del pasado strictu sensu, aunque algunas de esas páginas con- tuvieran este tipo de análisis. Pero de cualquier modo, se trataba de una obra universitaria resultado de una labor científica y que mostraba un grado importante de profesionalización, ejemplificando bien una modalidad del trabajo de investigación científica de la época. En efecto, un libro como La guerra europea y la política internacional... (1914), fue el producto de un ciclo de conferencias magistrales dadas por Del Valle Iberlucea a sus alumnos, de riguroso análisis bibliográfico más que documental, de las relaciones internacionales de las principales potencias europeas. ${ }^{16}$

En la medida en que pudo consolidar su tarea como docente universitario, estas obras expresaron una labor de estudio e investigación en la cual la cátedra era el espacio y condición de su producción. Tanto sus primeros textos jurídicos (fruto, como se señaló, de sus colaboraciones como estudiante en cursos de la Facultad de Derecho porteña) como estos últimos trabajos historiográficos de raíz docente, fueron la obra de un universitario que iba consolidando su erudición y dominio como especialista del derecho internacional y de la historia hispanoamericana. Pero difícilmente podría evaluarse que ellas serían los primeros pasos de una trayectoria de Del Valle Iberlucea como jurista y como historiador. En efecto, como expuso Buchbinder (2012) en su biografía de los Quesada, el trabajo académico dominante en el sistema universitario tenía

\footnotetext{
${ }^{16}$ Aunque este tipo de libros tenía una unidad de tema, su carácter de obra "contingente", se demostraba en su propio formato: contenía versiones taquigráficas de sus conferencias como docente y dos breves discursos parlamentarios. Este rasgo de formato se reproducirá en su libro, La cuestión internacional y el Partido Socialista (1917).
} 
un rasgo ensayístico, acorde a una universidad más profesionalista que científica: "en la que la identidad de los profesores y académicos se construía más que en su papel de científicos y universitarios en su condición de políticos y de profesionales liberales" (p. 202).

La labor académica de este socialista registraba así una producción que se reconocía tanto en la investigación científica como en el ensayismo. Pero a partir de su elección como senador nacional en 1913, toda su labor intelectual giró principalmente sobre su acción legislativa, alejándolo de una posible carrera volcada a la investigación en la cátedra, en la que continuó desarrollando sólo una tarea docente. Y ello se demuestra con gran parte de su producción intelectual entre ese último año y su desafuero parlamentario en junio de 1921. Estas nuevas publicaciones fueron la tarea de un político profesional, de un publicista socialista y en menor medida, la de un profesor especializado en historia y derecho internacional. Sus distintas publicaciones de este periodo fueron las conferencias, discursos y proyectos parlamentarios que brindó como político y senador socialista y sus artículos periodísticos como director del diario La Vanguardia. Al igual que su libro La guerra europea (1914), La cuestión internacional y el Partido Socialista (1917) fue la obra que aunó la labor del político profesional y del docente universitario, reuniendo escritos de origen partidario, parlamentario y de sus clases. En la edición de este último primaba un interés político partidario, ya que Del Valle Iberlucea justificaba su publicación no en razones de difusión de saberes científicos entre los estudiantes y universitarios sobre la realidad internacional, sino más bien en que podría incidir en las disputas internas del Ps frente a la Gran Guerra. $^{17}$

Sin embargo, toda su obra expuso una condición singular de lo que debía ser el trabajo universitario, en el que Del Valle Iberlucea enfatizaba que la ciencia debía fundar la acción intelectual en la cátedra, diferenciando claramente la práctica vocacional y hasta diletante en ella (que había caracterizado a gran parte de los universitarios aún avanzada la primera década del siglo) de la investigación científica, que reivindicaba plenamente. Pero al igual que gran parte del discurso universitario del periodo, Del Valle Iberlucea argumentó que era la ciencia la que debía fundar a la acción política. En los tres años previos a su desafuero parlamentario y a su muerte poco después (en agosto de 1921), fue consejero académico en la Facultad de Filosofía y Letras porteña durante el decanato reformista del filósofo Alejandro Korn y en la de Ciencias Jurídicas de La Plata, defendiendo en ambas las propuestas impulsadas por el reformismo del ' 18 . El conflicto desatado por el estudiantado de clases medias visibilizó a la universidad ante la dirigencia socialista como un espacio más - pero en su dimensión cultural- de la disputa política con la elite dominante, que abría la posibilidad de

${ }^{17}$ En una nota introductoria el editor del libro afirmaba: "Comprende este libro una serie de artículos publicados en LA VANGUARDIA, algunos discursos pronunciados en el Senado de la Nación y varias lecciones dictadas en la cátedra de Derecho Internacional de la Universidad de La Plata. [...] Se justifica su recopilación en este volumen por el debate suscitado últimamente en el seno del Partido Socialista, con motivo de la actitud de sus parlamentarios en el Congreso al votar la ruptura de relaciones diplomáticas con Alemania." (Del Valle Iberlucea, 1917).

\section{()(1)}


poner en jaque el control de esa agencia educativa por parte de sus intelectuales. Las protestas de los estudiantes llevaron a los socialistas a apoyarla, tanto por su identificación social y política con ellos como por las propuestas de democratización de su gobierno y de profesionalización de las carreras y disciplinas que reclamaban. A partir de esa lectura el Ps y estos profesores apoyaron las demandas estudiantiles de cambio universitario e incluyeron en su programa mínimo de 1918 el postulado de "Democratización de las universidades y extensión popular de su enseñanza" (Partido Socialista, 1945, p. 10). Si bien Del Valle Iberlucea apoyó las protestas de los estudiantes, coincidió con sus demandas y alcanzó nuevamente cargos de dirección universitaria gracias a ellas, en esos últimos años se dedicó de lleno al estudio y defensa de la revolución bolchevique en Rusia, de la que terminó siendo uno de sus publicistas y la que implicó en él una verdadera inflexión en sus posiciones políticas, llevándolo a apoyar la incorporación del PS a la Tercera Internacional. Estas posiciones le valieron además del ya señalado desafuero parlamentario y un juicio por desacato, el reclamo de expulsión del profesorado del Colegio Nacional de Buenos Aires por parte de sus colegas. ${ }^{18}$

\section{Trayectoria académica de Alfredo PALACIOS}

La docencia universitaria de Palacios comenzó en 1910 en la Facultad de Derecho

\footnotetext{
${ }^{18}$ Las posiciones de Del Valle Iberlucea frente a la revolución rusa pueden seguirse en Enrique del Valle Iberlucea (1920) y en su libro póstumo La revo-
}

de la que había egresado, siendo designado profesor suplente de Filosofía del Derecho. Esa inicial y marginal inserción académica estuvo precedida de una fulgurante carrera en las filas del Ps desde su incorporación en 1901 que lo había llevado a ser electo como diputado nacional durante dos periodos (1904-1907 y 19121915) y sin dudas fue un aspecto valorado en su nombramiento, ya que Palacios aparecía en esa casa de estudios para ofrecer la enseñanza de las ideologías obreras (Halperin, 2001). Su tesis rechazada había sido publicada en 1900 por Sesé y Larrañaga, bajo el título La miseria en la República Argentina y fue clave para hacerlo conocido en las filas del PS y comenzar su trayectoria en él. A su vez, Palacios desplegó en esa primera década del nuevo siglo una intensa labor legislativa y de militancia partidaria, junto al ejercicio liberal de la abogacía (aunque con dedicación particular a la defensa de trabajadores y militantes socialistas). Pero su inserción docente marginal se modificó hacia 1915 con su nombramiento como profesor titular de Legislación Industrial en la Facultad de Ciencias Económicas. Su acceso a ambas cátedras le brindó así la posibilidad de iniciar una carrera académica primero en la facultad, cuyos colegas articulaban su profesión férreamente con el sistema de poder, y en otra como la de Ciencias Económicas, de carácter novísimo que, aunque con fuerte presencia de los juristas de la anterior, mostraba una apertura a las preocupaciones temáticas laborales y sindicales del movimiento obrero. Desde 1915 Pala-

lución rusa (1934). Un análisis de sus posiciones frente a la revolución y el proceso político-judicial reaccionario que generaron, en Kohan (2000, pp. 55-64); Becerra (2009, pp. 109-161). 
cios pudo en esta última diseñar un curso de estudios en torno a la cuestión legal y sindical obrera. Pero ese fue el año también en el que vivió su primer gran contraste en su carrera política que lo alejó de la misma hasta fines de 1930, ya que fue expulsado del Ps y renunció a su banca de diputado nacional. Esa situación lo llevó a concentrarse de lleno en la actividad profesional y en las nuevas cátedras. ${ }^{19}$

Las protestas estudiantiles reformistas de Córdoba, Buenos Aires y La Plata promovieron a Palacios como uno de los referentes de la renovación científica y educativa de las aulas universitarias, y esa promoción tuvo efectos académicos concretos en su carrera. En la coyuntura de auge del reformismo estudiantil (entre 1918 y 1925), fue designado por ese movimiento como su vocero en el viaje que realizó a las universidades de Perú en 1919 y obtuvo, por moción del Centro de Estudiantes de Derecho de Buenos Aires, el apoyo de las autoridades de su facultad para desarrollar en ella ese mismo año y en 1920 un curso libre de "Legislación del trabajo". Asimismo, las autoridades de Ciencias Económicas (un año después) apoyaron su plan de llevar adelante una investigación experimental sobre las condiciones de trabajo en el puerto de la Boca. Estas nuevas iniciativas académicas le permitieron desenvolver un trabajo científico influido por autores socialdemócratas, por las nuevas codificaciones del dere-

\footnotetext{
${ }^{19}$ Palacios intentó junto con un pequeño grupo de socialistas liderar una alternativa partidaria al Ps, con la fundación ese mismo año del Partido Socialista Argentino, la que sin embargo se frustró rápidamente, obligándolo a concentrarse en la actividad universitaria a lo largo de toda la década de los veinte (Luna, 1999).
}

cho laboral y por los estudios de psicología experimental europeos sobre el trabajo industrial. Si antes de 1918 Palacios no había dado cuenta aún de escritos científicos, desde 1919 la Revista de Ciencias Económicas contaría con un número significativo de sus colaboraciones. En este último año publicó "El Código Civil Argentino y los obreros" y "Los trabajadores en la Argentina”. Un año después publicó en esa misma revista los artículos "Derecho internacional obrero" y "Los sindicatos de trabajadores en la Cámara de Diputados". Pero su libro mayor sería El nuevo derecho, publicado en 1920 y dedicado a la crítica de las codificaciones del derecho civil de tradición liberal y al análisis de las luchas obreras, de sus organizaciones sindicales y de la legislación laboral. En este libro formulaba su propuesta de desarrollo de los estudios jurídicos sobre la base de la investigación científica empírica, que inscribía como parte de la propuesta del reformismo universitario:

Ahora, la reforma tiene raigambre fuerte en todas las universidades de la República [...] No hay ciencia sin el estudio de los hechos, sin la investigación como método, que es la observación sistematizada de esos hechos (Palacios, 1934).

Palacios inscribió en esa definición de lo que debía ser el trabajo científico universitario, una condición de legitimidad social que pasaba por la vinculación del mismo con el estudio científico de los intereses y demandas de la clase obrera y, más genéricamente, del pueblo. Esta vinculación era decisiva a su criterio en la construcción por la universidad, de formulaciones jurídicas que garantizaran los derechos de aquel, atribuyéndole así a la 
ciencia practicada en ella una función social, que era el estudio de la realidad del mundo de los trabajadores. Según su criterio, del cumplimiento estricto de ese vínculo derivaba la legitimidad del saber científico producido en el seno de aquella. La obra apuntaba a mostrar la superación de las concepciones decimonónicas del derecho burgués por las nuevas corrientes jurídicas, fundadas en el solidarismo social y que reconocían el avance político de la clase obrera (Graciano, 2008, pp. 91-96). Fue en el libro La fatiga y sus proyecciones sociales, de 1922, con el cual expuso en toda su dimensión su propuesta para la enseñanza del derecho, en el que vinculó ciencia jurídica y crítica del capitalismo industrial. Este libro reunía los informes de una serie de experiencias científicas que en 1921 llevó adelante entre los obreros del Estado en el barrio de la Boca, desde la cátedra de Legislación Industrial y en los que registró las consecuencias psicofísicas que producía en sus organismos la jornada laboral de ocho horas, recurriendo a los métodos de la psicología experimental. Allí propuso que la legislación del trabajo debía formularse a partir de los resultados que en los laboratorios instalados en las fábricas obtuvieran los abogados sobre las condiciones laborales. A partir de estas investigaciones, Palacios (1944) sostuvo que el desarrollo de las ciencias jurídicas debía fundarse sobre los métodos experimentales de la psicología y aplicarse en particular para el estudio del desenvolvimiento laboral bajo el capitalismo.

Los libros El nuevo derecho y La fatiga fueron una dura crítica de la ciencia jurídica liberal y a partir de ellos Palacios fue construyendo una carrera académica y configurando un nuevo discurso sobre la fun- ción social del derecho y la legislación. Así definió y promovió un programa para la renovación de la enseñanza de las facultades de Ciencias Jurídicas y del perfil profesional del abogado, sustentado en su definición del derecho como una ciencia social, en su propuesta de formular una nueva legislación a través de ensayos científicos vinculados a la psicología experimental y de la introducción del derecho laboral como rama específica de los estudios jurídicos. Sus libros mostraban las concepciones teóricas y jurídicas del socialismo reformista para transformar la juridicidad burguesa y las presentaba como una alternativa a las experiencias de cambio revolucionarias como la bolchevique (Herrera, 2001, pp. 303-310).

Convertido en figura nacional y continental del reformismo universitario y apoyado por el estudiantado, la carrera académica de Palacios alcanzaría su punto más alto al ser designado profesor de Política Económica en 1921 de la Facultad de Ciencias Jurídicas de la UNLP y un año después decano de la misma. En su decanato (1922-1925) impulsó reformas en la enseñanza que buscaron redefinir el perfil profesional de sus egresados. Entre otras medidas profundizó el recambio del profesorado, la apertura a la enseñanza del derecho laboral, promovió los seminarios e incorporó la psicología experimental en los estudios jurídicos, creando un laboratorio de esa disciplina en la facultad. Para Palacios la universidad debía convertirse en un centro de investigación de los problemas sociales y de las nuevas ideologías que pugnaban en la posguerra y su gestión fue un ensayo de renovación de los estudios del derecho, que se orientó a generar nuevos saberes jurídicos y a formar nuevos grupos de juristas con un perfil 
profesional renovado, capaces de dar cuenta de esos desafíos sociales y políticos.

En esa década de los veinte Palacios completó una plena carrera científica y profesional en la universidad como docente titular en las facultades de Ciencias Jurídicas platense y de Ciencias Económicas porteña y como miembro de la Academia de Ciencias Económicas, alcanzando también cargos académicos relevantes, al ser designado consejero superior en la UBA y en la UNLP. Sus artículos y libros de estos años muestran la consolidación de una labor académica en torno a las propuestas del derecho laboral y la consideración del derecho como una ciencia social fundada en la investigación empírica, reivindicando para el estudio de la historia argentina, tanto el enfoque materialista marxista, como la perspectiva teórica del socialismo y el ideario del antiimperialismo latinoamericanista y de la democracia social (Palacios, 1926, pp. 1-28). ${ }^{20}$ Pero en obras como La universidad nueva (1925), Universidad y democracia (1928) y La democratización de la enseñanza (1930), Palacios aparecía más como el universitario portador de un nuevo proyecto de universidad, la reformista. Allí sus escritos postulaban su labor de gestor institucional de esa nueva universidad en La Plata y en Buenos Aires, dando cuenta de su tarea científica y docente, publicitando su acción como gestor universitario del modelo de universidad reformista en sus consejos. Sus intervenciones en los debates en el consejo superior de la UBA en 1927 contra un nuevo régimen de admisión al ingreso en la carrera de Medicina (promovido por el

${ }^{20}$ En su discurso en la Academia de Ciencias Económicas de 1926, Palacios defendió la interpretación materialista de la historia argentina.
Consejo Directivo de esa Facultad y el médico Bernardo Houssay) (Cibotti, 1997, pp. 60-63) y en el de la UNLP en 1930, proponiendo la gratuidad de la enseñanza superior, reforzaron ese papel de promotor de un modelo de universidad que pretendía expresar las demandas educativas del reformismo estudiantil.

Su identificación plena con el reformismo universitario hizo también que su carrera en los cargos de dirección académica dependiera siempre de los avances y retrocesos de ese movimiento. Así, los nuevos avances reformistas le posibilitaron ser electo decano de la Facultad de Derecho porteña en julio de 1930 y en esa gestión se propuso otra vez llevar adelante su propuesta de renovación educativa, la que consideraba que satisfacía por completo las demandas del movimiento estudiantil. Pero aunque su decanato porteño se llevó adelante en una facultad cuyos profesores habían rechazado siempre el reformismo, el fracaso de su gestión se debió más bien a las consecuencias que sobre esa facultad y la propia UBA tuvo la crisis política nacional, más que a la oposición antirreformista. En efecto, esa crisis llevó a Palacios, y a todo el cuerpo universitario, a participar en su desenlace: el derrocamiento de Yrigoyen en septiembre de ese año. Sin embargo, tuvo otro no esperado por ellos, ya que la implantación de la dictadura de Uriburu colocó al reformismo entre los sectores más perjudicados por el fin de la experiencia democrática, obligando a Palacios a renunciar. En un gesto final, Palacios, proclamando su condición de autoridad universitaria, desconoció al nuevo gobierno y reclamó la restitución del orden democrático y la convocatoria a elecciones. En ese último acto de oponerse al nuevo régimen,

\section{()(1)}


Palacios produjo una forma de intervención intelectual en la política desde la particular plataforma institucional que le otorgaba el ejercicio de la dirección de una casa de estudios universitarios. ${ }^{21}$

\section{TrayeCtOria ACADÉmiCA DE ENRIQUE MOUCHET}

Incorporado a la enseñanza universitaria desde 1919 como profesor suplente del curso de Psicología Experimental que dictaba Horacio Piñero en la Facultad de Filosofía y Letras porteña, Mouchet inició con ella su carrera docente, aunque la misma contaba como paso previo a la de nivel medio. Como ya se indicó, Mouchet se había formado en los estudios de psicología y medicina y partía de una especialización en esas disciplinas que le habían permitido desarrollar diversos trabajos científicos desde su graduación, como Psicofisiología del genio y del talento (1909). Pero su acceso a la cátedra fue resultado del vínculo discipular con Piñero y su consolidación en ella, como profesor titular desde 1921, se debió a la vacancia de la misma por la enfermedad y muerte de este último (Foradori, 1941; Papini, 1978 , p. 234). La orientación hacia el estudio de la psicología desde un enfoque médico experimental se había impuesto desde temprano en los dos cursos de la materia dictados en la Facultad de Filosofía y Letras, a partir del trabajo en ellos

${ }^{21}$ Como consecuencia del golpe de Estado de 1930, Palacios se reintegró a las filas del viejo Ps y recomenzó una carrera partidaria que lo llevó nuevamente al Congreso nacional en 1932, esta vez como senador por la ciudad de Buenos Aires (Graciano, 2008, pp. 193-284). de Piñero y de José Ingenieros, sentando toda una tradición científica en su seno, que sin embargo había causado diversos debates entre sus autoridades, las que pretendieron en distintos momentos que uno de sus cursos tuviera un enfoque filosófico (Buchbinder, 2005, pp. 56-58).

Mouchet inició así una carrera universitaria que se potenciaría rápidamente con la expansión institucional de las universidades que el reformismo provocó en esos años, para abandonarla recién en 1943 , cuando se acogió a su jubilación. Militante del PS desde su juventud y concejal en la ciudad de Buenos Aires por ese partido (entre 1920 y 1923), Mouchet fue junto con Del Valle Iberlucea uno de los dirigentes que defendió la experiencia revolucionaria bolchevique y la incorporación del Ps a la Tercera Internacional (Corbière, 1987, pp. 19-22 y 109-125). Llegaba a la enseñanza universitaria como parte de la renovación científica e ideológica de su profesorado reclamada por el reformismo estudiantil. Esto también pareció evidente con su designación en 1920 como profesor suplente en una cátedra de Psicología Experimental en la Facultad de Humanidades y Ciencias de la Educación de la UNLP, facultad creada ese mismo año por las demandas de los estudiantes, para superar el positivismo finisecular dominante en su enseñanza. En Humanidades Mouchet consolidó rápidamente su condición docente al ser nombrado profesor titular y alcanzó una ascendente influencia institucional bajo el programa reformista, siendo nombrado consejero académico de la facultad en 1922 y decano para el periodo 1924-1927. Sin embargo, si su designación se había sustentado en la creencia reformista de que Mouchet era el portador a la vez de la renovación 
científica e ideológica reclamada por los estudiantes platenses, la misma se fue disipando rápidamente, pero más por su práctica docente que por su gestión académica. En efecto, Mouchet se integró como profesor de la sección de Filosofía y Ciencias de la Educación y se vinculó al núcleo representativo del positivismo científico de enfoque clínico-médico, entre quienes se contaban psiquiatras y pedagogos como Christofredo Jacob, Rodolfo Senet, y Alfredo Calcagno. Esa sección era un espacio académico de fuertes disputas entre los filósofos ganados al antipositivismo y los educadores y médicos que buscaban profundizar los estudios de psicología desde la perspectiva médico-experimental. Sin la capacidad carismática de Palacios ni la condición de publicista de este para proponer un modelo renovado de universidad que satisficiera las demandas del profesorado y del movimiento reformista platense, Mouchet recibió permanentes críticas por parte de ambos sectores por la orientación de sus estudios de psicología, hasta que se vio obligado a renunciar en 1929. Pero, sin embargo, su docencia y decanato platense no dejaron de expresar una labor científica que remitía a los parámetros del reformismo universitario como eran la incorporación de nuevos profesores, la extensión universitaria y la implantación de la enseñanza de seminarios, la prédica del humanismo y latinoamericanismo y el solidarismo social de los estudiantes con los obreros. $^{22}$ Pero lo invalidado por el estu-

22 Los discursos como decano de Mouchet, "Política universitaria" y "Hacia la nueva universidad" de 1924, enfatizaban la prédica de compromiso cívico y político de los universitarios con el desenvolvimiento de una democracia social en Argentina. diantado fueron su enseñanza de cátedra y sus investigaciones concentradas en los estudios de psicología experimental y medicina, que expresaban bien el modelo científico positivista, cuyo referente era José Ingenieros y el proyecto intelectual encarnado por su Revista de Filosofía. En efecto, sus estudios como Evolución del problema de la afasia, El lenguaje de los ciegos, Las localizaciones cerebrales a la luz de la Psicología biológica (todos de 1919), De las estimulaciones bormonales del encéfalo (1920), El lenguaje interior y los trastornos de la palabra (1923), Contribución al estudio de la sensibilidad táctil (1928) y Un nuevo capitulo de psico-fisiología: el tacto a distancia o sentido de los obstáculos en los ciegos (1929) entre otros, mostraban el pleno dominio de una investigación científica hegemonizada por disciplinas como la fisiología y la neurología.

En este sentido, su desplazamiento de la cátedra provocado por la imposición estudiantil de su renuncia, fue el resultado de la querella que en el seno de la sección de Filosofía y Educación enfrentaban al idealismo y espiritualismo bergsoniano promovidos por Alejandro Korn, con el positivismo médico en psicología y educación que representaban Mouchet y Calcagno. Para Korn y sus discípulos, la formación en psicología experimental y las prácticas del laboratorio que implicaban eran las rémoras de un saber ya muerto en el que aún se pretendía formar a los estudiantes de filosofía. Sin embargo, difícil resulta imaginar a Mouchet como un científico anclado en una ciencia decimonónica, quien por el contrario mostraba una atención permanente a los desarrollos de los estudios médicos de neuropsiquiatría y los de psicología estadunidense y europea y una apertura 
intelectual singular: fue de los que tempranamente estudió en sus cursos y evaluó en artículos las posibilidades y déficits del psicoanálisis de Sigmund Freud (Mouchet, 1926, pp. 405-411; Vezzetti, 1996a, pp. 27-29; 1996b, pp. 131-136; Buchbinder, 2005, p. 120).

En esos mismos años veinte Mouchet continuó en su cátedra de Psicología en la Facultad de Filosofía y Letras porteña con los estudios de base experimental, en un ámbito académico también con creciente presencia antipositivista (y que contaba en ella con la de su feroz crítico Alejandro Korn) y en el que si bien no alcanzó posiciones de dirección institucional, fue más propicio a su desenvolvimiento profesional. Allí, junto a otros médicos y psicólogos experimentales, organizó y dirigió desde 1931 el Instituto de Psicología con su laboratorio experimental, desplegando a lo largo de la nueva década diversos estudios, todos de enfoque clínico y fisiológico (Klappenbach, 2006, pp. 126-130). Mouchet contribuyó así a profundizar el desarrollo de esta vertiente de una psicología articulada plenamente con el campo de la medicina, sección en la que participaban reconocidos médicos de su especialidad, como José L. Alberti, Osvaldo Loudet y el ya citado Christofredo Jakob, entre otros. La práctica docente y científica de Mouchet era más bien la expresión de la "colonización" de la psicología por las corrientes de la medicina, más que ser una rémora intelectual, reflejando sus programas de curso el dominio de las temáticas de enfoque fisiológico y biológico. Lo que mostraba bien su labor universitaria era el desenvolvimiento de un plan de investigaciones científicas sostenidas en torno al laboratorio y que produjo numerosas investigaciones y la consolidación en la Universidad de Buenos Aires de un espacio institucionalizado de estudios de psicología experimental (que ya tenía su tradición) con publicaciones y formación de discípulos, mereciendo el reconocimiento de sus pares especializados en psicología y psiquiatría con su participación en él. La consolidación académica de estos estudios se expresaba en el reconocimiento científico nacional e internacional de Mouchet, que le permitió liderar en 1930 la fundación de la Sociedad de Psicología de Buenos Aires, de la que fue su primer presidente (Plotkin, 2003).

\section{CONCLUSIÓN: CIENCIA Y CÁTEDRA EN LOS} UNIVERSITARIOS DE IZQUIERDA

Los itinerarios en la universidad de estos profesionales revelaban ciertos rasgos comunes en sus carreras académicas y en su trabajo científico. Una formación profesional tramada por supuestos educativos y científicos positivistas y evolucionistas, orientada tanto hacia su ejercicio autónomo (en el foro judicial o el consultorio médico), a la enseñanza media y universitaria, como a la cooptación al servicio en la burocracia estatal o en el sistema político. Su inserción académica ocurrió con una escasa trayectoria intelectual previa y siendo jóvenes los tres, pero mientras en los casos de Palacios y Mouchet fue inicialmente marginal, en el de Del Valle Iberlucea implicó su incorporación al círculo más granado de la ciencia positivista para participar en su misma dirección. Salvo en el caso de Palacios, las relaciones discipulares construidas en su condición de estudiantes influyeron claramente en sus capacitaciones profesiona- 
les y en sus especializaciones de trabajo científico, así como también en el acceso a las cátedras universitarias. Para Palacios y Mouchet los cambios reformistas fueron decisivos en impulsar sus carreras docentes, permitiéndoles también alcanzar la dirección de facultades y desenvolver en ellas sus propuestas de reforma educativa.

La obra producida por Del Valle Iberlucea y Palacios en el marco universitario reflejó parcialmente la construcción de un corpus bibliográfico marxista y socialista, aunque ambos reivindicaron el materialismo histórico como una teoría científica desde la cual estudiar en la cátedra el pasado argentino. Pero aun así, no es posible definir la tarea de enseñanza que desplegaron como marxismo de cátedra. Por el contrario, las características de sus incorporaciones a la enseñanza, sus especializaciones científicas y profesionales y las afinidades teóricas y metodológicas que expresaron en torno al saber jurídico, desempeñaron su papel en delimitar las temáticas de sus programas de cátedra. En tanto, Mouchet se orientó a continuar y profundizar una psicología anclada en el paradigma de las corrientes médicas y aun con la crisis del positivismo en el campo de la filosofía, nunca fue permeable a buscar alternativas a ellas, como la que le pudo ofrecer la teoría psicoanalítica que conocía y enseñó en sus cursos. Paradójicamente, Mouchet fue (como Del Valle Iberlucea), un socialista que apoyó fervientemente la revolución bolchevique y el ingreso del PS a la Internacional Comunista, pero esas transformaciones que afectaban también el mundo cultural y científico no provocaron cambios en su labor universitaria, anclada firmemente en la psicología experimental. Su propia trayectoria partidaria tampoco se modi- ficó a pesar de sus posiciones radicalizadas ideológicamente, ya que continuó en las filas del Ps a lo largo de las décadas de los veinte y los treinta. En tanto Del Valle Iberlucea compartía los supuestos evolucionistas de la ciencia positivista (asumida por casi todos los socialistas del periodo), y aunque uno de ellos era la futura organización de un mundo de relaciones internacionales fundado en el socialismo, su enseñanza del Derecho Internacional estuvo dominada por la orientación de la escuela francesa de Louis Renault. Aunque estudioso del materialismo histórico y luego defensor de la revolución rusa, sus programas no daban cuenta de una bibliografía que permitiera abrir el estudio del derecho internacional a ese enfoque, y su muerte prematura clausuró, probablemente, el desarrollo de sus cursos en esa dirección. Pero al igual que Palacios, defendió la implantación de reformas sociales por medio de una ingeniería jurídica que superara el derecho liberal. Fueron sin dudas los programas de cursos de Palacios en las facultades de Derecho porteña y platense, pero principalmente en la de Ciencias Económicas, los que llevaron a fondo una propuesta de cambio tanto en la enseñanza como en la labor científica. La introducción de toda una bibliografía de autores socialdemócratas que postulaban el derecho laboral y la implementación de una metodología de investigación científica de lo jurídico fundada en la psicología experimental, fue su gran innovación. Pero aunque Palacios defendió el materialismo marxista y su enseñanza, como lo atestigua su discurso de 1926 en la Academia Nacional de Ciencias Económicas, nunca fue marxista ni desarrolló en estos años estudios jurídicos o históricos desde esa perspectiva. 
Si bien todos ellos promovieron la prédica de una labor intelectual centrada en la investigación científica y por momentos desarrollaron obras que fueron el fruto de su práctica, sólo Mouchet la sostuvo en el tiempo y se asoció claramente a lo que junto con Palacios consideraba su expresión más lograda: el trabajo del laboratorio. Así, su tarea académica asumió los rasgos de una práctica científica crecientemente profesionalizada y valoraron la autonomía de la cátedra para el desenvolvimiento de su labor intelectual. Su extensa permanencia al frente de la misma les permitió desarrollar orientaciones teóricas y de investigación, difundir líneas bibliográficas y de estudio, generar discipulazgos y lo evidente pero no menos importante: construir una carrera académica. Pero también defendieron una acción intelectual que implicaba la acción partidaria y su intervención en la vida pública, rechazando de plano un modo de labor científico que los aislara de la vida social e incomunicara su producción de las problemáticas sociales y políticas. Parte de la obra jurídica de Del Valle Iberlucea y de Palacios expresaba la preocupación de dar elaboración científica a los derechos obreros y de la mujer. La aspiración de ambos fue fundar científicamente desde la historia y las ciencias jurídicas, la política partidaria y parlamentaria. Sin dudas, los cargos directivos en la universidad fueron claramente utilizados también como plataforma de sus intervenciones públicas como intelectuales, de tono estridente en Palacios y moderado en Mouchet, difundiendo desde esas posiciones una prédica democrática socialista y latinoamericanista. En definitiva, los itinerarios universitarios de Del Valle Iberlucea, Palacios y Mouchet en este periodo mostraban, por un lado, una labor intelectual profesionalizada de acuerdo a los cánones de la práctica científica universitaria. Por otro, esos itinerarios académicos se articularon de modo positivo con la práctica política, con la que completaban su labor intelectual, que se pretendía también fruto del método de la ciencia. Esta concepción del trabajo intelectual era la que viabilizaba la articulación entre sus prácticas política y científico-académica. En este sentido, si como dirigentes y legisladores socialistas impulsaron propuestas de legislación en materia laboral y civil que buscaban garantizar los derechos sociales de la clase obrera y los de las mujeres en la esfera jurídica y política, como juristas y psicólogos su labor científica en la universidad demuestra que ella se desplegó orientada por la ideología y el programa de reformas de la sociedad de su partido.

\section{LISTA DE REFERENCIAS}

-Adelman, J. (1992). Socialism and democracy in Argentina in the age of the second International. Hispanic American Historical Review, 72(2), 211-238.

-Altamirano, C. (2001). Peronismo y cultura de izquierda. Buenos Aires: Siglo XXI.

-Altamirano, C. (2004). Entre el naturalismo y la psicología: el comienzo de la ciencia social en la Argentina. En F. Neiburg y M. Plotkin (comps.), Intelectuales y expertos. La constitución del conocimiento social en la Argentina (pp. 31-65). Buenos Aires: Paidós.

-Altamirano, C. (2006). Intelectuales. Notas de investigación. Bogotá: Grupo Editorial Norma.

-Barrancos, D. (1996). La escena iluminada. Ciencia para trabajadores, 1890-1930. Buenos Aires: Plus Ultra. 
-Becerra, M. (2009). Marxismo y feminismo en el primer socialismo argentino. Enrique del Valle Iberlucea. Buenos Aires: Prohistoria.

-Biagini, H. (comp.) (1999). La Universidad de La Plata y el movimiento estudiantil. Desde sus orígenes hasta 1930. La Plata: UNLP.

-Bohoslavsky, E. y Soprano, G. (eds.) (2010). Un Estado con rostro humano. Funcionarios e instituciones estatales en Argentina (desde 1880 a la actualidad). Buenos Aires: Prometeo Libros.

-Buchbinder, P. (1997). Historia de la Facultad de Filosofía y Letras. Universidad de Buenos Aires. Buenos Aires: EUDEBA.

-Buchbinder, P. (2005). Historia de las universidades argentinas. Buenos Aires: Sudamericana.

-Buchbinder, P. (2012). Los Quesada. Letras, ciencias y politica en la Argentina, 1850-1934. Buenos Aires: Edhasa.

-Camarero, H. y Herrera, C. (eds.) (2005). El Partido Socialista en Argentina. Sociedad, política e ideas a través de un siglo. Buenos Aires: Prometeo Libros.

-Camarero, H. (2007). A la conquista de la clase obrera. Los comunistas y el mundo del trabajo en la Argentina, 1920-1935. Buenos Aires: Siglo XXI.

-Cibotti, E. (1997). Alfredo Palacios en defensa de la universidad democrática. Pensamiento Universitario, año 5(6), 60-63.

-Corbière E. J. (1987). El marxismo de Enrique del Valle Iberlucea. Buenos Aires: Centro Editor de América Latina.

-Foradori, A. I. (1941). Enrique Mouchet. Una vida. Una vocación. Buenos Aires: Instituto Cultural Joaquín V. González.

-Fréderic, S., Graciano, O., Soprano, G. (comps.) (2010). El Estado argentino y las profesiones liberales, académicas y armadas. Rosario: Ediciones Prohistoria.

-García Costa, V. O. (1988). La miseria en la República Argentina. Buenos Aires: Centro Editor de América Latina [núm. 243].
-García Costa, V. O. (1998). Alfredo Palacios. Entre el clavel y la espada. Una biografía. Buenos Aires: Planeta.

-Graciano, O. (2003a). Intelectuales, ciencia y política en la Argentina neoconservadora. La experiencia de los universitarios socialistas. Revista de Estudios Interdisciplinarios de América Latina y el Caribe-EIAL, 14(2), julio-diciembre, 51 a 70.

-Graciano, O. (2008). Entre la torre de marfil y el compromiso político. Intelectuales de izquierda en la Argentina, 1918-1955. Bernal: Editorial de la Universidad Nacional de Quilmes.

-Graciano, O. (2010). Hombres de izquierda, profesión y producción de conocimiento social en la Argentina. En S. Fréderic, O. Graciano, G. Soprano (comps.), El Estado argentino y las profesiones liberales, académicas y armadas (pp. 81-112). Rosario: Ediciones Prohistoria.

-Halperin Donghi, T. (2001). Vida y muerte de la República verdadera (1910-1930). Buenos Aires: Ariel.

-Halperin Donghi, T. (2002). Historia de la Universidad de Buenos Aires. Buenos Aires: Eudeba.

-Herrera, C. (2001). Socialismo jurídico y reformismo político en Carlos Sánchez Viamonte. Revista de Estudios Políticos, 113, julio- septiembre, 303-310.

-Klappenbach, H. (2006). Periodización de la psicología en Argentina. Revista de Historia de la Psicología, 27(1), 109-164.

-Kohan, N. (2000). De Ingenieros al Che. Ensayos sobre el marxismo argentino y latinoamericano. Buenos Aires: Biblos.

-Luna, F. (1999). Alfredo Palacios. Buenos Aires: Sudamericana.

-Mouchet, E. (1926). Significación del psicoanálisis. Revista Humanidades, t. 12, 405-411. Publicación de la Facultad de Humanidades y Ciencias de la Educación-UNLP.

-Neiburg, F. y Plotkin, M. (comps.) (2004). Intelectuales y expertos. La constitución del cono- 
cimiento social en la Argentina. Buenos Aires: Paidós.

-Palacios, A. (1926). La interpretación económica de la historia [separata núm. 56, pp. 1-28]. Buenos Aires: Universidad de Buenos Aires.

-Palacios, A. (1934). El nuevo derecho (1920). Buenos Aires: Claridad.

-Palacios, A. (1944). La fatiga y sus proyecciones sociales (1922). Buenos Aires: Claridad.

-Palacios, A. (1957). La Universidad Nueva. Desde la reforma universitaria hasta 1957. Buenos Aires: M. Gleizer.

-Papini, M. (1978). La psicología experimental argentina durante el periodo 1930-1955.

Revista Latinoamericana de Psicología, año 10(2), 227-258. Bogotá.

-Partido Socialista (1945). La reforma universitaria y el Partido Socialista. Buenos Aires: Casa del Pueblo.

-Pereyra, D. (1999). Fantasmas, fanáticos e iluminados en la Universidad de Buenos Aires. Reformismo, socialismo y política en el debate sobre el marxismo en las clases de sociología durante la primera década del siglo. Estudios Sociales, año 9(16), 41-56.

-Pérez Perdomo, R. (2008). Los juristas como intelectuales y el nacimiento de los Estados naciones en América Latina. En Altamirano, C. (dir.), Historia de los intelectuales en América Latina. I La ciudad letrada, de la conquista al modernismo (pp. 168-183). Buenos Aires: Katz Editores.

-Plotkin, M. (2003). Freud en las pampas. Orígenes y desarrollo de una cultura psicoanalítica en la Argentina (1910-1983). Buenos Aires: Sudamericana.

-Rapoport, M. y Seoane, M. (2007). Buenos Aires. Historia de una ciudad (t. 1). Buenos Aires: Planeta.

-Solari, J. A. (1972). Enrique del Valle Iberlucea. Primer senador socialista de América. Buenos Aires: Bases.

-Tarcus, H. (dir.) (2007). Diccionario biográfico de la izquierda argentina. De los anarquistas a la "nueva izquierda" (1870-1976). Buenos Aires: Emecé.

-Tarcus, H. (2007). Marx en la Argentina. Sus primeros lectores obreros, intelectuales y científicos. Buenos Aires: Siglo XXI.

-Universidad Nacional de La Plata (1910). Digesto de la Universidad Nacional de La Plata. Buenos Aires: Imprenta de Coni Hermanos.

-Valle Iberlucea, E. del (1914). La guerra europea y la política internacional [Lecciones sobre la Historia de las relaciones internacionales de Europa en el siglo XIX, dictadas en la Facultad de Filosofía y Letras]. Buenos Aires: Talleres gráficos Riachuelo.

-Valle Iberlucea, E. del (1917). La cuestión internacional y el Partido Socialista. Buenos Aires: Martin García editor.

-Valle Iberlucea, E. del (1920). La doctrina socialista y los consejos obreros. Buenos Aires: Editorial Adelante.

-Valle Iberlucea, E. del (1929). Teoría Materialista de la Historia. En Marx, C. et al., Interpretación económica de la Historia. Manifiesto Comunista [Comentarios y estudios] (pp. 145-185). Buenos Aires: Biblioteca de Estudios Sociales "Juan B. Justo".

-Valle Iberlucea, E. del (1934). La Revolución Rusa [Obra inédita]. Buenos Aires: Claridad.

-Vallejo, G. (2007). Escenarios de la cultura científica argentina. Ciudad y Universidad (18821955). Madrid: CSIC.

-Vezzetti, H. (1996a) Freud en Buenos Aires (1989). Bernal: Universidad Nacional de Quilmes.

-Vezzetti, H. (1996b). Aventuras de Freud en el país de los argentinos. De José Ingenieros a Enrique Pichon-Rivière. Buenos Aires: Paidós.

-Walter, R. (1977). The Socialist Party of Argentina 1890-1930. Austin: Institute of Latin American Studies-The University of Texas.

-Zimmermann, E. (1995). Los liberales reformistas. La cuestión social en la Argentina, 18901916. Buenos Aires: Sudamericana. 


\section{BIBLIOGRAFÍA}

-Buchbinder, P. (2000). El movimiento reformista de 1918: una perspectiva desde la historia interna de la Universidad de Buenos Aires. Estudios Sociales, 19, segundo semestre, 37-63.

-Graciano, O. (1998). Universidad y economía agroexportadora: el perfil profesional de los ingenieros agrónomos, 1910-1930. En GirbalBlacha, N. (dir. y comp.), Agro, universidad y enseñanza. Dos momentos de la Argentina rural (1910-1955) (pp. 13-72). La Plata: Universidad Nacional de La Plata.

-Graciano, O. (2003b). Estado, Universidad y economía agroexportadora en Argentina: el desarrollo de las facultades de Agronomía y Veterinaria de Buenos Aires y La Plata, 19041930. Theomai, 8, segundo semestre. Recuperado de www.revistatheomai.unq.edu.ar

-Marianetti, B. (1972). Enrique del Valle Iberlucea. Una bonesta conducta frente a la revolución rusa. Buenos Aires: Sílaba.

-Mouchet, E. (1924a). Política universitaria [discurso de colación]. Revista Humanidades, t. 9, 317-326. Publicación de la Facultad de
Humanidades y Ciencias de la Educación-UNLP.

-Mouchet, E. (1924b). Hacia la nueva Universidad. Revista de Filosofía, año 10(5), septiembre, 196-203.

-Mouchet, E. (1925a). Nuevas orientaciones sociales en la Enseñanza Pública. Revista Humanidades, t. 11, 433-443. Publicación de la Facultad de Humanidades y Ciencias de la Educación-UNLP.

-Mouchet, E. (1925b). José Ingenieros. Revista Humanidades, t. 11, 1-8. Publicación de la Facultad de Humanidades y Ciencias de la Educación-UNLP.

-Mouchet, E. (1929). La humanización del proletariado por la enseñanza técnica profesional. Revista Humanidades, t. 19, 121-142. Publicación de la Facultad de Humanidades y Ciencias de la Educación-UNLP.

-Palacios, A. (1921). La Revolución Rusa. Buenos Aires: Agencia Sudamericana de Libros.

-Palacios, A. (1961). Nuestra América y el Imperialismo. Buenos Aires: Palestra.

Valle Iberlucea, E. del (1931). Justicia y Trabajo. Rosario: Talleres Gráficos Editorial La Tierra. 